\title{
Global transcriptome analysis of different stages of preimplantation embryo development in river buffalo
}

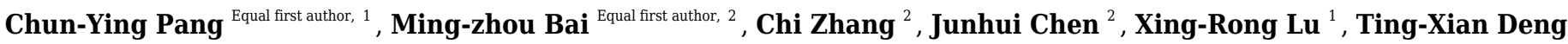 \\ ${ }^{1}$, Xiao-Ya Ma ${ }^{1}$, An-Qin Duan ${ }^{1}$, Sha-sha Liang ${ }^{1}$, Yun-Qi Huang ${ }^{3}$, Zhihui Xiu ${ }^{\text {Corresp., }}{ }^{2}$, Xian-Wei Liang ${ }^{\text {Corresp. } 1}$ \\ ${ }^{1}$ Key Laboratory of Buffalo Genetics, Breeding and Reproduction technology, Ministry of Agriculture and Rural Affairs (Guangxi), Guangxi Buffalo Research \\ Institute, Chinese Academy of Agricultural Sciences, Nanning, P. R. China \\ 2 BGI-Shenzhen, BGI Genomics, Shenzhen, China, P. R. China \\ ${ }^{3}$ Shandong Agricultural University, Taian, P. R. China \\ Corresponding Authors: Zhihui Xiu, Xian-Wei Liang \\ Email address: xiuzhihui@genomics.cn, liangbri@126.com
}

Background: Water buffalo (Bubalus bubalis) are divided into river buffalo and swamp buffalo subspecies and are essential livestock for agriculture and the local economy. Studies on buffalo reproduction have primarily focused on optimal fertility and embryonic mortality. There is currently limited knowledge on buffalo embryonic development, especially during the preimplantation period. Assembly of the river buffalo genome offers a reference for omics studies and facilitates transcriptomic analysis of preimplantation embryo development (PED).

Methods: We revealed transcriptomic profile of four stages (2-cell, 8-cell, Morula and Blastocyst) of PED via RNA-seq (Illumina HiSeq4000). Each stage comprised three biological replicates. The data were analyzed according to the basic RNA-seq analysis process. Ingenuity analysis of cell lineage control, especially transcription factor (TF) regulatory networks, was also performed.

Results: A total of 21,519 expressed genes and 67,298 transcripts were predicted from approximately $81.94 \mathrm{~Gb}$ of raw data. Analysis of transcriptome-wide expression, gene coexpression networks, and differentially expressed genes (DEGs) allowed for the characterization of gene-specific expression levels and relationships for each stage. The expression patterns of TFs, such as POU5F1, TEAD4, CDX4 and GATAs, were elucidated across diverse time series; most TF expression levels were increased during the blastocyst stage, during which time cell differentiation is initiated. All of these TFs were involved in the composition of the regulatory networks that precisely specify cell fate. These findings offer a deeper understanding of PED at the transcriptional level in the river buffalo. 
1 Global Transcriptome Analysis of Different Stages of

\section{Preimplantation Embryo Development in River Buffalo}

3 Chun-Ying Pang ${ }^{1 \dagger}$, Ming-Zhou Bai ${ }^{2 \dagger}$, Chi Zhang ${ }^{2}$, Junhui Chen ${ }^{2}$, Xing-Rong Lu ${ }^{1}$, Ting-Xian

4 Deng ${ }^{1}$, Xiao-Ya Ma ${ }^{1}$, An-Qin Duan ${ }^{1}$, Sha-sha Liang ${ }^{1}$, Yun-Qi Huang ${ }^{3}$, Zhihui Xiu ${ }^{2 *}$ and Xian-

5 Wei Liang $1 *$

$7{ }^{1}$ Key Laboratory of Buffalo Genetics, Breeding and Reproduction technology, Ministry of 8 Agriculture and Rural Affairs (Guangxi), Guangxi Buffalo Research Institute, Chinese Academy

9 of Agricultural Sciences, Nanning, P. R. China

102 BGI Genomics, BGI-Shenzhen, Building No. 7, BGI Park, No. 21 Hongan $3^{\text {rd }}$ Street, Yantian

11 District, Shenzhen 518083, P. R. China

$12{ }^{3}$ Shandong Agricultural University, Taian, Shandong, P. R. China

* Corresponding Author:

Zhihui Xiu

No. 21, Hongan $3^{\text {rd }}$ Street, Yantian District, Shenzhen 518083, P. R. China

Xian-wei Liang

No. 24, Yongwu Street, Nanning 530001, Guangxi, P. R. China

E-mail: liangbri@126.com

$\dagger$ These authors had equal contributions in this study

\section{Abstract}

Background: Water buffalo (Bubalus bubalis) are divided into river buffalo and swamp buffalo subspecies and are essential livestock for agriculture and the local economy. Studies on buffalo reproduction have primarily focused on optimal fertility and embryonic mortality. There is currently limited knowledge on buffalo embryonic development, especially during the preimplantation period. Assembly of the river buffalo genome offers a reference for omics studies and facilitates transcriptomic analysis of preimplantation embryo development (PED).

Methods: We revealed transcriptomic profile of four stages (2-cell, 8-cell, Morula and Blastocyst) 
31 of PED via RNA-seq (Illumina HiSeq4000). Each stage comprised three biological replicates. The

32 data were analyzed according to the basic RNA-seq analysis process. Ingenuity analysis of cell

33 lineage control, especially transcription factor (TF) regulatory networks, was also performed.

34 Results: A total of 21,519 expressed genes and 67,298 transcripts were predicted from approximately $81.94 \mathrm{~Gb}$ of raw data. Analysis of transcriptome-wide expression, gene coexpression networks, and differentially expressed genes (DEGs) allowed for the characterization of gene-specific expression levels and relationships for each stage. The expression patterns of TFs, such as POU5F1, TEAD4, CDX4 and GATAs, were elucidated across diverse time series; most TF expression levels were increased during the blastocyst stage, during which time cell differentiation is initiated. All of these TFs were involved in the composition of the regulatory networks that precisely specify cell fate. These findings offer a deeper understanding of PED at the transcriptional level in the river buffalo.

\section{Introduction}

Water buffalo (Bubalus bubalis) is a species of the Bubalus genus in the Bovidae family; these buffalo are primarily distributed in tropical and subtropical regions (Nanda, 2003). According to morphological and behavioral traits, water buffalo are classified into river buffalo and swamp buffalo (Michelizzi et al., 2010). As an important livestock source, the river buffalo provides draft power in agriculture and is a producer of milk and meat in several Asian countries (Wang et al., 2017). Although the river buffalo has clear economic importance in agriculture, its reproduction is still limited by long calving intervals, late puberty, and seasonal anestrus (Guelfi et al., 2017).

2 Studies concerning the reproduction of river buffalo have primarily focused on selection of 
53 optimal fertility through methods such as good nutrition condition and short-day fertility

54 (Campanile, 2007; Campanile et al., 2010), with a goal of avoiding embryonic mortality, which is

55 highly correlated withmaternal progesterone concentrations (Neglia et al., 2008). The mechanisms

56 underlying preimplantation embryo development (PED) are unknown in the river buffalo.

57 However, gene expression and regulation of the preimplantation embryo are critical for early cell

58 fate decisions and transitions from totipotent to lineage specific cells (Saiz and Plusa, 2013).

59 Transcriptomic profiling, either globally level or at the single-cell level, has been applied to the

60 study PED in model animals (mouse and bovine) and in humans. As a result, expression patterns,

61 transcriptional regulators (including transcription factors, IncRNAs and circular RNAs), and

62 epigenomic reprogramming mechanisms have been revealed at representative stages of PED in

63 these species (Xie et al. 2010; Biase et al. 2014; Graf et al. 2014; Fan et al. 2015; Guo et al. 2017),

64 resulting in successive waves of signal regulators and gene regulatory networks being established

65 in PED (Xie et al. 2010; Vassena et al. 2011; Zuo et al. 2016). However, research on PED, even

66 with respect to expression patterns and gene regulatory networks, is limited in the river buffalo.

67 Here, we report the global transcriptomic profiling for four stages of the preimplantation embryo (2-Cell, 8-Cell, Morula and Blastocyst) in the river buffalo. RNA-seq analysis from these four stages revealed gene expression patterns of the early phase of embryo development, characterized transcription in PED, and provided information on the regulatory networks involved in cell fate decisions and genetic control of early cell lineages. These results offer new insight into

72 PED of the river buffalo.

\section{Materials and Methods}

\section{Ethics statement}


Protocols were based on the Principles of the Administration of Experimental Animals issued by the Ministry of Science and Technology (Beijing, China) in 1988 (most recent version in 2001). The project was approved by the Institutional Review Board of BGI (NO. FT19030). All experiments were approved and supervised by the Animal Care and Use Committee of Guangxi Buffalo Research Institute.

\section{Oocyte collection and maturation culture in vitro}

Based on a previously reported manual (Liang et al. 2008), ovarian follicles were collected from three different living river buffalos (Mora958, Mora1088 and Mora1172) by the Ovum PickUp (OPU) method. Collected ovarian follicles were stored in the Storage Buffer (Table S3). Oocytes with more than three layers of granulosa cells were selected out under a stereoscopic microscope. After washing with the Storage Buffer three times, oocytes were incubated in glass plates with the Culture Medium (Table S3) at $39^{\circ} \mathrm{C}$ and $5 \% \mathrm{CO}_{2}$ saturated air humidity.

\section{Preparation of granulosa cells}

Per the description by Liang et al. (2008), cumulus cells were eliminated from maturated oocytes after culturing for 22-24 hours. Maturated granulosa cells were washed by the Culture Medium two times and suspended at a concentration of $\sim 2 \times 10^{6} \mathrm{cell} / \mathrm{ml}$. A $30 \mu 1 \mathrm{microdroplet}(10-$ 15 maternal eggs) was plated into the plastic plate (35 mm diameter), covered with paraffin oil, and cultured for 30 minutes at $39^{\circ} \mathrm{C}$ and $5 \% \mathrm{CO}_{2}$ saturated air humidity.

\section{In vitro fertilization (IVF) and zygote culture}

4 Sperms were selected for 30 minutes in the Swimming-up Buffer (Table S3). Selected sperm were washed with the Fertilization Buffer (Table S3), and cocultured with mature maternal egg microdroplet in the Fertilization Buffer. The final sperm concentration was $1 \sim 1.5 \times 10^{6} / \mathrm{ml}$. The 
97 mixture was incubated for approximately 18 hours. After eliminating sperm on the surface, zygotes were washed in the Embryo Culture Solution (Table S3) two-three times and transferred to single layer culture plates for incubation at $39^{\circ} \mathrm{C}$ and $5 \% \mathrm{CO}_{2}$ saturated air humidity (Pang et al. 2010).

\section{RNA extraction and RNA-seq library preparation}

Total RNA was extracted from zygotes at each stage by using Single Cell RNA-Seq library construction protocol (Illumina, San Diego, CA, USA). RNA integrity was asssessed via an Agilent Technologies 2100 Bioanalyzer. RNA-seq library preparation was performed as described previously (Williams et al., 2017). Seq-ready libraries were sequenced on the HiSeq 4000 platform (Illumina, San Diego, CA, USA).

\section{Data filtering and genome mapping}

Raw reads were filtered by using SOAPnuke (Options = -1 10 -q 0.3 -n 0.05 -i) (BGI, Shenzhen, China). The criteria were as follows: 1) reads contain adaptors; 2) reads with unknown nucleotides $>=5 \%$; and 3) low quality reads (the rate of reads whose quality value $<=10$ is more than $20 \%$ ). The river buffalo genome was used as a reference genome (Williams et al., 2017). Genome mapping was performed by using the HISAT (hierarchical indexing for spliced alignment of transcripts) method (Options = --phred64 --sensitive --no-discordant --no-mixed -I 1 -X 1000). Transcripts were reconstructed via StringTie (Options $=$-f 0.3 -j 3 -c 5 -g 100 -s 10000 -p 8) and predicted using Cuffcompare tool in Cufflink (Trapnell et al., 2010; Pertea et al., 2016).

\section{Gene expression and transcriptome-wide time series analysis}

Clean reads were mapped to the reference genome via the Bowtie 2 method (Options $=-\mathrm{q}--$ phred64 --sensitive --dpad 0 --gbar 99999999 --mp 1,1 --np 1 --score-min L,0, -0.1 -I 1 -X 1000 --no-mixed --no-discordant -p 1 -k 200) (Langmead et al., 2018). Gene expression levels were 
119 calculated using the RSEM (v 1.2.12) method (Options = --forward-prob 0.5) (Li and Dewey

120 2011). Genes with similar expression patterns were clustered according to Mfuzz (Options = -c 12

$121-\mathrm{m}$ 1.25) (Kumar and Futschik 2007).

122

123

124

125

126

127

128

129

130

131

132

133

134

135

136

137

138

139

140

\section{Gene coexpression and differentially expressed genes}

A gene coexpression network was constructed through WGCNA (weighted correlation network analysis) (threshold $=0.8$, minModuleSize $=20$, deepSplit=2, power $=22$ ). The differentially expressed genes (DEGs) analysis was performed by using DEGseq (fold change $>=2$, adjusted P value $<=0.001$ ) (Wang et al., 2010) and PossionDis (fold change $>=2.00$, FDR $<=0.001$ ) (Soneson and Delorenzi 2013). GO (gene ontology) terms for both co-expressed genes and DEGs were assigned according to the best-hits BLASTx, which were derived from Blast2GO (v2.5.0) alignments against the GO database (release-20120801). DEGs were aligned against KEGG (Kyoto Encyclopedia of Genes and Genomes) by the BLASTx package with E-value $<=10^{-5}$ as the threshold.

\section{Results}

\section{RNA-seq and mapping to the reference genome}

To obtain transcriptomic information from different stages of PED in the river buffalo, we used the Illumina HiSeq platform to sequence twelve samples consisting four stages (2-Cell, 8Cell, Morula and Blastocyst) with three biological replicates each. Approximately $81.94 \mathrm{~Gb}$ of raw data (bases) were generated. After filtering low quality reads, unknown nucleotides, and contained adapters from the raw reads, we obtained approximately $75.72 \mathrm{~Gb}$ of clean data (bases) with an average $6.31 \mathrm{~Gb}$ for each sample. Using the river buffalo genome as a reference (Williams et al., 2017), the average mapping ratio of each sample was $\sim 81.65 \%$. Details were shown in Table 1 . 
141 The quality of these RNA-seq data was satisfactory to perform further analysis, including gene 142 expression statistics, transcriptome-wide time series expression profiling, coexpression and DEG 143 detection and $\mathrm{TF}$ analysis.

\section{Gene expression statistics}

145

146

147

148

149

150

151

152

153

154

155

156

157

158

159

160

161

162

To elucidate gene expression profiles of the four stages of PED in the river buffalo, we annotated aligned reads based on the reference genome. The results revealed that 21,519 genes were expressed, which including 19,031 known genes and 2,488 novel genes. Among the 67,298 annotated transcripts, 28,136 transcripts with novel alternative splicing subtypes encoded known proteins, 2,512 transcripts were defined as novel protein coding genes, and 36,650 transcripts were classified into long non-coding RNAs. Details of each sample are shown in Table S1 and Figure S1.

Venn analysis elucidated distinct and common genes expressed among the four stages of PED (Fig. 1a). This analysis revealed 660, 260, 289, and 515 specifically expressed genes in 2C (2cell), 8C (8-Cell), MS (Morula), and BL (Blastocyst) stages, respectively. Furthermore, 15,978 genes were commonly expressed among these four stages. After filtering genes that had inconsistent FPKM values in the three biological replicates, we used mean FPKM values of the three replicates for cluster analysis (Fig. 1b). Cluster results indicated that functionally relevant genes showed similar expression patterns. In summary, combining transcript statistics of twelve samples with Venn and cluster analyses revealed gene expression profiles of the four stages of PED in the river buffalo.

\section{Transcriptome-wide time series expression profiling}

Transcriptome-wide time series expression profiling is an efficient way to cluster genes that 
163 show similar expression patterns across different stages. To detect gene time series expression in

164 four stages of PED, we employed Mfuzz to perform this cluster analysis (Kumar and Futschik

165 2007). (Fig. 2). These clusters exhibited genes with specific expression patterns. In detail, clusters

$1661,2,3$ and 4 comprised genes that were specifically expressed in 2C, 8C, MS and BL, respectively

167 (Fig. 2 A-D). Genes in cluster 5 showed decreasing expression with PED progression (Fig. 2 E).

168 In contrast, genes in cluster 6 were increasingly expressed with PED progression (Fig. 2 F).

During PED, the expression levels of genes involved in the control of cell lineage are pivotal

170 for embryonic development (Saiz and Plusa, 2013). In the time series expression profiling, we

171

172

173

174

175

176

177

178

179

180

181

182

183

184

185

isolated genes reportedly involved in early cell fate decisions during embryonic development to perform ingenuity analysis (Guo et al., 2010; Rossant, 2018). Among them, POU5F1 and YAP1 showed high expression levels at the beginning of PED, and POU5F1 showed a higher expression level during the BL stage (Fig. 3a). TEAD4 began to show increased expression in the MS stage (Fig. 3a), while most of the other genes (except $S O X 2$ ) showed an increased expression level in the BL stage (Fig. 3 b). SOX2 expression was upregulated in the $8 \mathrm{C}$ stage and peaked in the MS stage (Fig. 3b). These findings indicate that genetic control of cell lineage is activated during PED, and variant expression patterns might be due to the different roles of these genes in the regulatory network of cell fate decisions.

\section{Gene coexpression network analysis}

We used WGCNA (weighted correlation network analysis) to detect gene coexpression networks at different stages of PED. Five modules were clustered by gene expression similarity and gene frac threshold (0.5) (Fig. S2). Nodes in the figure represent coexpressed genes, and line width indicates the coexpression relevance between genes. The larger the node is, the higher the connectivity of the gene. Genes with high connectivity are located in the center of the network and 
186

187

188

189

190

191

192

193

194

195

196

197

198

199

200

201

202

203

play a key role in the whole module. Some genes with low connectivity but similar expression patterns are clustered as submodules (Fig. S2a). Such analysis provides information about key genes and their coexpression networks in PED (Table S2). We also performed correlation analysis between different modules (Fig. S2b). The relationship among different coexpression modules provides insight into horizontal levels of gene expression regulation (Table S2).

To gain information about the biological systems in which coexpressed genes participate, we performed gene ontology (GO) analysis of these coexpression modules (Fig. S3). In brief, cellular processes and biological regulation in the category Biological Processes, cell and cell parts in the category Cellular Components, and binding and catalytic activity in the category Molecular Function were significantly enriched in all coexpression modules. Such enrichments were highly correlated with active status during PED.

\section{Differentially expressed gene (DEG) detection}

To distinguish DEGs at each stage, we used DEGseq (Wang et al., 2010) and PossionDis (Soneson and Delorenzi 2013) to test for difference between each stage. The distribution of DEGs for each comparison is shown via MA plot (Robinson et al., 2009) (Fig. 4a). Significantly up- and down- regulated genes are shown in Figure 4b. All comparisons between the BL stage and any other stage (2C, 8C and MS) identified over 5000 up- and down- regulated DEGs, suggesting that gene expression during the BL stage is the most highly variable (Fig. 4b). $2 \mathrm{C}-\mathrm{VS}-8 \mathrm{C}$ and $8 \mathrm{C}-\mathrm{VS}-$ MS, two adjacent stage comparisons, exhibited fewer DEGs and fewer differences in expression levels (Fig. 4b, c). These findings indicate that gene expression profiling is more variable during the BL stage and less different between adjacent stages.

To illuminate the biological processes that participate in the four stages of the PED, we 
208

209

210

211

212

213

214

215

216

217

218

219

220

221

222

223

224

225

226

227

228

229

230

annotated the DEGs of each comparison according to both GO terms and KEGG pathway analysis. The top significantly enriched GO terms of DEGs in all comparisons were related to developmental processes, such as cellular and metabolic processes in Biological Process, cell/cell part in Cellular Component, and binding and catalytic activity in Molecular Function (Fig. S4). KEGG pathway annotation revealed the most dramatic variation occurred in metabolic pathway, which should be activated during cell division and differentiation (Fig. S5). Interestingly, pathways in cancer, which might result in cell compaction, were enriched in the $8 \mathrm{C}$-VS-MS, at which time the embryo begins polarization during compaction (Jedrusik 2015; Niu et al. 2017). These annotations suggest that processes and pathways related to development are activated in PED, reflecting pathways enriched in cell status transition between $8 \mathrm{C}$ and MS stages.

\section{Transcription factor (TF) analysis}

Regulation of gene expression in PED is critical for cell division and differentiation (Ma et al., 2001). As transcriptional regulators, TFs play essential roles in the genetic control of early cell lineages (Guo et al., 2010) and suppose are thought to condition the distinct expression profiling during the four stages of PED. Therefore, we annotated TFs encoding genes identified as DEGs and classified families of the TFs (Fig. 5a). Many families, such as the zinc finger and bHLH families, function in PED (Jones 2004; Guo et al. 2018). Among these TFs, we isolated several predicted to be essential for cell fate decision for ingenuity analysis, unraveling their expression patterns according to the transcriptome-wide time series expression profiling (Fig. 5b). GATA6, TCF7L1 and $J U N B$ exhibited low expression levels in the $2 \mathrm{C}$ and $8 \mathrm{C}$ stages, increasing expression levels in the MS stage, and high expression levels in the BL stage (Fig. 5b). The expression levels of $N A N O G$ and GRB7 were higher in $8 \mathrm{C}$ and MS stages than in the BL stage (Fig. 5b). ATF7IP2 was highly expressed at the beginning of PED and maintained similar expression levels in the $2 \mathrm{C}$, 
$2318 \mathrm{C}$ and MS stages; however, ATF7IP2 was downregulated in the BL stage (Fig. 5b). The 232 expression patterns of these TFs were distinct at different stages of PED, suggesting that their 233 differential expression is required during the control of cell lineage.

\section{Discussion}

Preimplantation is the stage that initiates from zygote to blastocyst in mammalian (Rossant, 2018). The study of preimplantation embryos provides pivotal clues for genetic diagnosis (human), embryonic programming, and cell fate decisions (Duranthon et al. 2008; Biase et al. 2014; Wang et al. 2019). Transcriptomic profiling of the preimplantation of humans and model animals has been performed both at the global transcriptome and single-cell transcriptome levels (Huang and Khatib 2010; Yan et al. 2013; Biase et al. 2014; Jiang et al. 2014). However, few studies are reported in buffalo. Our study unraveled the global transcriptomic profiles of PED in the river buffalo. Basic analysis of the RNA-seq data, which characterized the gene expression patterns, gene coexpression modules, and DEGs, not only creates a data foundation for further study of PED but also provides clues for the ingenuity analysis of specific pathways. For example, KEGG pathway analysis of the DEGs between different stages revealed that pathways in cancer were enriched, indicating that a few regulatory pathways in cancer are similar to those of PED. Such similarity, including ontogenesis and its crucial factors, was also reported in the comparison between the cancer stem cells and para-embryonic stem cells (Manzo 2019).

Cell fate decisions in PED compose a complicated process that requires many regulators, such as microRNA (miRNA) and TFs (Guo et al., 2010; Gurtan and Sharp, 2013). Studies in mice have revealed lineage tracing and TFs involved in cell fate decisions (Guo et al., 2010; Saiz and Plusa, 2013). Among the numerous TFs, we chose key TFs for ingenuity analysis, revealing their 
253 expression patterns and analyzing possible genetic interaction hierarchy in the river buffalo (Fig.

254 6). In brief, POU5F1(OCT4)/SOX2 (negative), CDX2, and GATA3 are three parallel downstream 255 effectors of TEAD4/YAP1 (Loh et al., 2006; Home et al., 2009; Ralston et al., 2010). Negative 256 feedback between $C D X 2$ and OCT4 is essential for cell status stabilization (Niwa et al., 2005). 257 GATA3 shares downstream targets with CDX2 (Home et al., 2009). The regulation between ETS2 258 and $C D X 2$ is inhibited by $O C T 4 / S O X 2$ (Rossant, 2018). NANOG and $C D X 2$ repress each other and 259 NANOG plays a subservient role to OCT4 (Chen et al. 2009). GATA6 and NANOG might repress each other's transcription (Wamaitha et al. 2015). Such regulation is reflected by their expression patterns in the river buffalo (Fig. 3 and 5). Along with the increasing expression level of TEAD4, expression levels of $C D X 2$ and GATA3 were upregulated, and the $S O X 2$ expression level was downregulated. Subsequently, decreased inhibition of $S O X 2$ release the regulation between ETS2 and $C D X 2$, resulting in upregulation of ETS2 expression. The expression patterns of $N A N O G$ and GATA6 showed an opposite pattern. Interestingly, as the subservient role of OCT4, NANOG was expressed in a manner similar to the OCT4 expression patterns during the $8 \mathrm{C}$ and MS stages, but did not increase in the BL stage. This difference may be due to the increasing expression level of $C D X 2$. The expression level of OCT4 was extremely high, supporting that OCT4 is required for blastocyst formation (Daigneault et al. 2018).

Furthermore, expression patterns of other related TFs in PED indicated that they play roles in cell fate decisions in the river buffalo. In detail, TCF7L1, which mediate the Wnt signaling pathway, is necessary in pluripotent cells to prepare them for lineage specification (Hoffman et al. 2013). JUNB, which belongs to AP-1 family and is involved in JAK-STAT signaling pathway, plays function in regulating gene activity (Yamazaki et al. 2017; Yu et al. 2018). The reason of their increased expression might be that cell division and differentiation are activated during the 
276 BL stage. GRB7 encodes a growth receptor-binding protein that participates in various cellular 277 signaling and functions (Tai et al. 2016). Its expression pattern showed high level at the 8C, MS 278 and BL stages, which was consistent with previous report in mice (Tanaka and Ko 2004).. 279 ATF7IP2is a member of MCAF/AM proteins, which are able to interact with a variety of molecules 280 to function as transcription modulators (Fujita et al. 2003; Cai et al. 2006). The high expression 281 level of $A T F 7 I P 2$ might be due to the participation in the transcription regulation in PED. All of 282 these TFs and other components compose a precisely regulatory network that controls cell lineages 283 in river buffalo preimplantation embryo development.

\section{Conclusion}

With RNA-seq data $(\sim 81.94 \mathrm{~Gb})$ from four stages of the PED in river buffalo, we characterized gene expression profiling, coexpression networks and DEGs. TF detection and transcriptome-wide time series expression analysis revealed TF expression patterns in the genetic control of cell linage. As regulators of cell fate decisions, TFs are involved in the construction of regulatory networks of cell lineage control.

\section{Conflicts of Interest}

The authors declare no conflicts of interest.

\section{Author contribution}

Zhihui Xiu and Xian-Wei Liang conceived and designed the experiments. Chun-Ying Pang, Xing-Rong Lu, Ting-Xian Deng and Ming-Zhou Bai performed the experiments. Xiao-Ya Ma, 
297 All authors read and approved the final manuscript.

\section{Acknowledgements}

299 This study was funded by the National Natural Science Foundation of China (No. 31660649), 300 the Guangxi Science and Technology Major Project (GKAA16450002), and the Guangxi Natural 301 Fund program (2017GXNSFAA198108).

The data reported in this study are also available in the CNGB Nucleotide Sequence Archive (CNSA: https://db.cngb.org/cnsa; accession number: CNP 0000305)

\section{Supplementary materials}

Fig. S1. Statistics of gene expression numbers in all samples.

Fig. S2. Gene coexpression analysis. (A) Five modules of coexpression networks. (B) Corelation of the five modules. Deeper yellow coloring indicates stronger correlation.

Fig. S3. GO analysis of coexpression modules.

Fig. S4. GO term annotation of DEGs for each comparison.

Fig. S5. KEGG pathway annotation of DEGs.

312 Table S1. Statistics of gene and transcript numbers in all samples.

313 Table S2. Coexpression modules and genes in all modules.

314 Table S3. Buffer formulas used in this study.

\section{Reference}


317 Alonso, C.R., 2002. Hox proteins: sculpting body parts by activating localized cell death. Current Biology. 12, R776-8.

319

320

321

322

323

324

325

326

327

328

329

330

331

332

333

334

335

336

337

Avilion, A.A., Nicolis, S.K., Pevny, L.H., Perez, L., Vivian, N. and Lovell-Badge, R., 2003. Multipotent cell lineages in early mouse development depend on SOX2 function. Genes \& Development. 17, 126-40.

Biase, F.H., Cao, X. and Zhong, S., 2014. Cell fate inclination within 2-cell and 4-cell mouse embryos revealed by single-cell RNA sequencing. Genome research. 24: 1787-1796.

Cai, H., Hu, J., Song, P. and Gong, W., 2006. PSM2, a novel protein similar to MCAF2, is involved in the mouse embryonic and adult male gonad development. Molecular biology reports. 33: 159-166.

Campanile, G., Baruselli, P.S., Neglia, G., Vecchio, D., Gasparrini, B., Gimenes, L.U., Zicarelli, L. and D'Occhio, M.J., 2010. Ovarian function in the buffalo and implications for embryo development and assisted reproduction. Animal Reproduction Science. 121, 1-11.

Campanile, G., Neglia, G., Gasparrini, B., Galiero, G., Prandi, A., Di Palo, R., D'Occhio, M.J. and Zicarelli, L., 2005. Embryonic mortality in buffaloes synchronized and mated by AI during the seasonal decline in reproductive function. Theriogenology. 63, 2334-40.

Campanile, G., 2007. Embryonic mortality in buffalo cows. Italy Journal of Animal Science. 6, 119-129.

Chambers, I., Colby, D., Robertson, M., Nichols, J., Lee, S., Tweedie, S. and Smith, A., 2003. Functional expression cloning of Nanog, a pluripotency sustaining factor in embryonic stem cells. Cell. 113, 643-55. 
338

339

340

341

342

343

344

345

346

347

348

349

350

351

352

353

354

355

356

357

Chen, L., Yabuuchi, A., Eminli, S., Takeuchi, A., Lu, C.W., Hochedlinger, K. and Daley, G.Q., 2009. Cross-regulation of the Nanog and Cdx2 promoters. Cell research. 19: 1052-1061.

Corsetti, M.T., Briata, P., Sanseverino, L., Daga, A., Airoldi, I., Simeone, A., Palmisano, G., Angelini, C., Boncinelli, E. and Corte, G., 1992. Differential DNA binding properties of three human homeodomain proteins. Nucleic Acids Research. 20, 4465-72.

Daigneault, B.W., Rajput, S., Smith, G.W. and Ross, P.J., 2018. Embryonic POU5F1 is Required for Expanded Bovine Blastocyst Formation. Scientific Report. 8: 7753.

du Puy, L., Lopes, S.M., Haagsman, H.P. and Roelen, B.A., 2011. Analysis of co-expression of OCT4, NANOG and SOX2 in pluripotent cells of the porcine embryo, in vivo and in vitro. Theriogenology. 75, 513-26.

Duranthon, V., Watson, A.J. and Lonergan, P., 2008. Preimplantation embryo programming: transcription, epigenetics, and culture environment. Reproduction. 135: 141-150.

Fan, X., Zhang, X., Wu, X., Guo, H., Hu, Y., Tang, F. and Huang, Y., 2015. Single-cell RNAseq transcriptome analysis of linear and circular RNAs in mouse preimplantation embryos. Genome biology. 16: 148.

Fujita, N., Watanabe, S., Ichimura, T., Ohkuma, Y., Chiba, T., Saya, H. and Nakao, M., 2003. MCAF mediates MBD1-dependent transcriptional repression. Molecular Cell Biology. 23: $2834-2843$.

Georgiades, P. and Rossant, J., 2006. Ets2 is necessary in trophoblast for normal embryonic anteroposterior axis development. Development. 133, 1059-68. 
358 Graf, A., Krebs, S., Zakhartchenko, V., Schwalb, B., Blum, H. and Wolf, E., 2014. Fine mapping

359

360

361

362

363

364

365

366

367

368

369

370

371

372

373

374

375

376

377

378

of genome activation in bovine embryos by RNA sequencing. Proceedings of the National Academy of Sciences of the United States of America. 111: 4139-4144.

Guelfi, G., Stefanetti, V., De Luca, S., Giontella, A., Barile, V.L. and Barbato, O., 2017. Serum microRNAs in buffalo cows: Potential biomarkers of pregnancy. Research in Veterinary Science. 115, 294-300.

Guo, F., Li, L., Li, J., Wu, X., Hu, B., Zhu, P., Wen, L. and Tang, F. 2017., Single-cell multiomics sequencing of mouse early embryos and embryonic stem cells. Cell research. 27: 967-988.

Guo, G., Huss, M., Tong, G.Q., Wang, C., Li Sun, L., Clarke, N.D. and Robson, P., 2010. Resolution of cell fate decisions revealed by single-cell gene expression analysis from zygote to blastocyst. Developmental Cell. 18, 675-85.

Guo, S., Yan, X., Shi, F., Ma, K., Chen, Z.J. and Zhang, C., 2018. Expression and distribution of the zinc finger protein, SNAI3, in mouse ovaries and pre-implantation embryos. Journal of Reproduction Development. 64: 179-186.

Gurtan, A.M. and Sharp, P.A., 2013. The role of miRNAs in regulating gene expression networks. Journal of Molecular Biology. 425, 3582-600.

Hoffman, J.A., Wu, C.I. and Merrill, B.J., 2013. Tcf711 prepares epiblast cells in the gastrulating mouse embryo for lineage specification. Development. 140: 1665-1675.Home, P., Ray, S., Dutta, D., Bronshteyn, I., Larson, M. and Paul, S., 2009. GATA3 is selectively expressed in the trophectoderm of peri-implantation embryo and directly regulates $\mathrm{Cdx} 2$ gene 
Huang, W. and Khatib, H., 2010. Comparison of transcriptomic landscapes of bovine embryos using RNA-Seq. BMC genomics. 11: 711.

Kumar, L. and Futschik, M., 2007. Mfuzz: a software package for soft clustering of microarray data. Bioinformatics. 5-7.

Jedrusik, A., 2015. Making the first decision: lessons from the mouse. Reproduction Medecine Biology. 14: 135-150.

Jiang, Z., Sun, J., Dong, H., Luo, O., Zheng, X., Obergfell, C., Tang, Y., Bi, J., O'Neill, R., Ruan, Y., Chen, J. and Tian, X., 2014. Transcriptional profiles of bovine in vivo preimplantation development. BMC genomics. 15: 756.

Jones, S., 2004. An overview of the basic helix-loop-helix proteins. Genome biology. 5: 226.

Laity JH, L.B. and Wright, P.E., 2001. Zinc finger proteins: new insights into structural and functional diversity. Current Opinion in Structural Biology. 11 (1), 39-46.

Langmead, B., Wilks, C., Antonescu, V. and Charles, R., 2018. Scaling read aligners to hundreds of threads on general-purpose processors, Bioinformatics. 1-12.

Liang, X., Zhang, X., Yang, B., Chen, M., Huang, F., Pang C., Liao, C., Qin G., Wei, S. and Huang, Y., 2008. Ovum pick-up in vivo and in-vitro embryo production in water buffaloes. Chin. J. Vet. Sci. 28, 1290-1232.

Li, B. and Dewey, C.N., 2011. RSEM: accurate transcript quantification from RNA-Seq data with or without a reference genome. BMC Bioinformatics. 12, 323. 
399

400

401

402

403

404

405

406

407

408

409

410

411

412

413

414

415

416

417

418

419

Loh, Y.H., Wu, Q., Chew, J.L., Vega, V.B., Zhang, W., Chen, X., Bourque, G., George, J., Leong, B., Liu, J., Wong, K.Y., Sung, K.W., Lee, C.W., Zhao, X.D., Chiu, K.P., Lipovich, L., Kuznetsov, V.A., Robson, P., Stanton, L.W., Wei, C.L., Ruan, Y., Lim, B. and Ng, H.H., 2006. The Oct4 and Nanog transcription network regulates pluripotency in mouse embryonic stem cells. Nature Genetics. 38, 431-40.

Ma, J., Svoboda, P., Schultz, R.M. and Stein, P., 2001. Regulation of zygotic gene activation in the preimplantation mouse embryo: global activation and repression of gene expression. Biology of Reproduction. 64, 1713-21.

Manzo, G., 2019. Similarities Between Embryo Development and Cancer Process Suggest New Strategies for Research and Therapy of Tumors: A New Point of View. Frontier Cell Development Biology. 7: 20.

Michelizzi, V.N., Dodson, M.V., Pan, Z., Amaral, M.E., Michal, J.J., McLean, D.J., Womack, J.E. and Jiang, Z., 2010. Water buffalo genome science comes of age. International Journal of Biological Sciences. 6, 333-49.

Nanda AS, N.T., 2003. Role of buffalo in the socioeconomic development of rural Asia, current status and future prospectus. Journal of Animal Science. 74(6), 443-55.

Neglia, G., Natale, A., Esposito, G., Salzillo, F., Adinolfi, L., Campanile, G., Francillo, M. and Zicarelli, L., 2008. Effect of prostaglandin F2alpha at the time of AI on progesterone levels and pregnancy rate in synchronized Italian Mediterranean buffaloes. Theriogenology. 69, 953-60.

Nichols, J., Zevnik, B., Anastassiadis, K., Niwa, H., Klewe-Nebenius, D., Chambers, I., Scholer, 
420

421

422
H. and Smith, A., 1998. Formation of pluripotent stem cells in the mammalian embryo depends on the POU transcription factor Oct4. Cell. 95, 379-91.

Nishioka, N., Yamamoto, S., Kiyonari, H., Sato, H., Sawada, A., Ota, M., Nakao, K. and Sasaki, H., 2008. Tead4 is required for specification of trophectoderm in pre-implantation mouse embryos. Mechanisms of Development. 125, 270-83.

Niu, N., Mercado-Uribe, I. and Liu, J. 2017. Dedifferentiation into blastomere-like cancer stem cells via formation of polyploid giant cancer cells. Oncogene. 36: 4887-4900.

Niwa, H., Toyooka, Y., Shimosato, D., Strumpf, D., Takahashi, K., Yagi, R. and Rossant, J., 2005. Interaction between Oct $3 / 4$ and $\mathrm{Cdx} 2$ determines trophectoderm differentiation. Cell. 123, 917-29.

Pang, C., Yang, C., Yang, B., Shang, J., Li, R., Zhang, X., Tang, G., Huang, F., Huang, J. and Liang, X., 2010. Effects of buffalo and bovine follicular fluid supplemented in vitro matureation (IVM) medium on in vitro fertilization. China Animal Husbandry and Veterinary Medicine. 37(4),162-166.

Pertea, M., Kim, D., Pertea, G.M., Leek, J.T. and Salzberg, S.L., 2016. Transcript-level expression analysis of RNA-seq experiments with HISAT, StringTie and Ballgown. Nature Protocal. 11, 1650-1667.

Phillips K, L.B., 2000. The virtuoso of versatility: POU proteins that flex to fit. Journal of Molecular Biology. 302 (5), 1023-39.

Ralston, A., Cox, B.J., Nishioka, N., Sasaki, H., Chea, E., Rugg-Gunn, P., Guo, G., Robson, P., Draper, J.S. and Rossant, J., 2010. Gata3 regulates trophoblast development downstream 
of Tead4 and in parallel to Cdx2. Development. 137, 395-403.

442

443

444

445

446

447

448

449

450

451

452

453

454

455

456

457

458

459

460

461

Rayon, T., Menchero, S., Nieto, A., Xenopoulos, P., Crespo, M., Cockburn, K., Canon, S., Sasaki, H., Hadjantonakis, A.K., de la Pompa, J.L., Rossant, J. and Manzanares, M., 2014. Notch and hippo converge on $\mathrm{Cdx} 2$ to specify the trophectoderm lineage in the mouse blastocyst. Developmental Cell. 30, 410-22.

Rayon, T., Menchero, S., Rollan, I., Ors, I., Helness, A., Crespo, M., Nieto, A., Azuara, V., Rossant, J. and Manzanares, M., 2016. Distinct mechanisms regulate Cdx2 expression in the blastocyst and in trophoblast stem cells. Scientific Report. 6, 27139.

Robinson, M.D., McCarthy, D.J. and Smyth, G.K., 2009. edgeR: a Bioconductor package for differential expression analysis of digital gene expression data. Bioinformatics. 26, 139140

Rossant, J., 2018. Genetic Control of Early Cell Lineages in the Mammalian Embryo. Annual Review of Genetics.

Saiz, N. and Plusa, B., 2013. Early cell fate decisions in the mouse embryo. Reproduction. 145, R65-80.

Soneson, C. and Delorenzi, M., 2013. Acomparison of methods for differnetial expression analysis of RNA-seq data. BMC Bioinformatics. 14, 91.

Strumpf, D., Mao, C.A., Yamanaka, Y., Ralston, A., Chawengsaksophak, K., Beck, F. and Rossant, J., 2005. Cdx2 is required for correct cell fate specification and differentiation of trophectoderm in the mouse blastocyst. Development. 132, 2093-102.

Tai, Y.L., Tung, L.H., Lin, Y.C., Lu, P.J., Chu, P.Y., Wang, M.Y., Huang, W.P., Chen, K.C., 
462

463

464

465

466

467

468

469

470

471

472

473

474

475

476

477

478

479

480

481

Lee, H. and Shen, T.L., 2016. Grb7 Protein Stability Modulated by Pin1 in Association with Cell Cycle Progression. PloS one. 11: e0163617.

Tanaka, T.S. and Ko, M.S., 2004. A global view of gene expression in the preimplantation mouse embryo: morula versus blastocyst. European Journal of Obstetrics \& Gynecology Reproductive Biololgy. 115 Suppl 1: S85-91.

Trapnell, C., Williams, B.A., Pertea, G., Mortazavi, A.M., Kwan, G., van Baren, M.J., Salzberg, S.L., Wold, B. and Pachter, L., 2010. Transcript assembly and quantification by RNA-Seq reveals unannotated transcripts and isoform switching during cell differentiation. Nature Biotechnology. 28, 511-515.

Vassena, R., Boue, S., Gonzalez-Roca, E., Aran, B., Auer, H., Veiga, A. and Izpisua Belmonte, J.C., 2011. Waves of early transcriptional activation and pluripotency program initiation during human preimplantation development. Development. 138: 3699-3709.

Vassilev, A., Kaneko, K.J., Shu, H., Zhao, Y and DePamphilis, M.L., 2001. TEAD/TEF transcription factors utilize the activation domain of YAP65, a Src/Yes-associated protein localized in the cytoplasm. Genes \& Development. 15:1229-41

Vecchio, D., Neglia, G., Di Palo, R., Prandi, A., Gasparrini, B., Balestrieri, A., D'Occhio, M.J., Zicarelli, L. and Campanile, G., 2010. Is a delayed treatment with GnRH, HCG or progesterone beneficial for reducing embryonic mortality in buffaloes? Reproduction in Domestic Animals. 45, 614-8. 
Ji, H. and Niakan, K.K. 2015. Gata6 potently initiates reprograming of pluripotent and differentiated cells to extraembryonic endoderm stem cells. Genes \& development. 29: 1239-1255.

Wang, L.Y., Rao, X.Q., Luo, Y.Q., Liu, B., Peng, C.F., Chen, D., Yan, K., Qian, Y.Q., Yang, Y.M., Huang, Y.Z., Chen, M., Sun, Y.X., Li, H.G., Ye, Y.H., Jin, F., Liu, H.L. and Dong, M.Y. 2019. Preimplantation genetic diagnosis and screening (PGD/S) using a semiconductor sequencing platform. Human Genomics. 13: 1.

Wang, L., Feng, Z., Wang, X., Wang, X. and Zhang, X., 2010. DEGseq: an R package for identifying differentially expressed genes from RNA-seq data. Bioinformatics. 26, 136138.

Wang, S., Chen, N., Capodiferro, M.R., Zhang, T., Lancioni, H., Zhang, H., Miao, Y., Chanthakhoun, V., Wanapat, M., Yindee, M., Zhang, Y., Lu, H., Caporali, L., Dang, R., Huang, Y., Lan, X., Plath, M., Chen, H., Lenstra, J.A., Achilli, A. and Lei, C., 2017. Whole Mitogenomes Reveal the History of Swamp Buffalo: Initially Shaped by Glacial Periods and Eventually Modelled by Domestication. Scientific Report. 7, 4708.

Wang, Y., Smedberg, J.L., Cai, K.Q., Capo-Chichi, D.C. and Xu, X.X., 2011. Ectopic expression of GATA6 bypasses requirement for Grb2 in primitive endoderm formation. Developmental Dynamics. 240, 566-76.

Williams, J.L., Iamartino, D., Pruitt, K.D., Sonstegard, T., Smith, T.P.L., Low, W.Y., Biagini, T., Bomba, L., Capomaccio, S., Castiglioni, B., Coletta, A., Corrado, F., Ferre, F., Iannuzzi, L., Lawley, C., Macciotta, N., McClure, M., Mancini, G., Matassino, D., Mazza, R., 
Milanesi, M., Moioli, B., Morandi, N., Ramunno, L., Peretti, V., Pilla, F., Ramelli, P., Schroeder, S., Strozzi, F., Thibaud-Nissen, F., Zicarelli, L., Ajmone-Marsan, P., Valentini, A., Chillemi, G. and Zimin, A., 2017. Genome assembly and transcriptome resource for river buffalo, Bubalus bubalis $(2 \mathrm{n}=50)$. Gigascience. 6, 1-6.

Xie, D., Chen, C.C., Ptaszek, L.M., Xiao, S., Cao, X., Fang, F., Ng, H.H., Lewin, H.A., Cowan, C. and Zhong, S., 2010. Rewirable gene regulatory networks in the preimplantation embryonic development of three mammalian species. Genome research. 20: 804-815.

Yagi, R., Kohn, M.J., Karavanova, I., Kaneko, K.J., Vullhorst, D., DePamphilis, M.L. and Buonanno, A., 2007. Transcription factor TEAD4 specifies the trophectoderm lineage at the beginning of mammalian development. Development. 134, 3827-36.

Yamazaki, S., Tanaka, Y., Araki, H., Kohda, A., Sanematsu, F., Arasaki, T., Duan, X., Miura, F., Katagiri, T., Shindo, R., Nakano, H., Ito, T., Fukui, Y., Endo, S. and Sumimoto, H., 2017. The AP-1 transcription factor JunB is required for Th17 cell differentiation. Scientific Report. 7: 17402.

Yan, L., Yang, M., Guo, H, Yang, L., Wu, J., Li, R., Liu, P., Lian, Y., Zheng, X., Yan, J., Huang, J., Li, M., Wu, X., Wen, L., Lao, K., Li, R., Qiao, J. and Tang, F., 2013. Single-cell RNA-Seq profiling of human preimplantation embryos and embryonic stem cells. Nature structural \& molecular biology. 20: 1131-1139.

Yu, C., Zhang, X., Wang, L., Liu, Y., Li, N., Li, M., Chen, L., Liu, Y. and Yao, Y., 2018. Interleukin-6 regulates expression of Fos and Jun genes to affect the development of 
mouse preimplantation embryos. J Obstet Gynaecol Res 44: 253-262.

524

525

526

527

528

529

530

531

532

533

534

535

536

537

538

539

540

541

542

543

Zuo, Y., Su, G., Wang, S., Yang, L., Liao, M., Wei, Z., Bai, C. and Li, G., 2016. Exploring timing activation of functional pathway based on differential co-expression analysis in preimplantation embryogenesis. Oncotarget. 7: 74120-74131.

\section{Figure legends}

Fig. 1. Gene expression statistics of four stages of river buffalo preimplantation embryo development. (A) Venn analysis of distinct and common genes expressed in in four stages. (B) Cluster analysis of expressed genes via FPKM values for three replicates.

Fig. 2. Transcriptome-wide time series cluster of expressions profiling through the different stages. (A-D) Genes that were specifically expressed in 2C, 8C, MS and BL, respectively. (E) Genes decreasing expression with PED progression. (F) Genes were increasingly expressed with PED progression.

Fig. 3. Expression pattern of genes involved in cell fate decisions in preimplantation embryo development. (A) Genes with high expression levels (FPKM: 15-90) in all four stages. (B) Genes with relatively low expression levels $(\mathrm{FPKM}<15)$. SD indicates three biological replicates.

Fig. 4. Differentially expressed gene (DEG) analysis. (A-F) MA plot of DEGs in each two-stages comparison. (G) Up- and down- regulated DEGs in each comparison. (H) Cluster analysis of DEGs.

Fig. 5. DEG transcription factor (TF) analysis . (A) Statistics of TF numbers and families. (B) Time series expression of TFs involved in cell linage control. SD indicates three biological 
544 replicates.

545 Fig. 6. TF interaction hierarchy of cell lineage genetic control in river buffalo (Rossant, 2018).

546

547

548 
Figure 1

Gene expression statistics of river buffalo PED

Gene expression statistics of four stages of river buffalo preimplantation embryo development. (A) Venn analysis of distinct and common genes expressed in in four stages.

(B) Cluster analysis of expressed genes via FPKM values for three replicates.

A

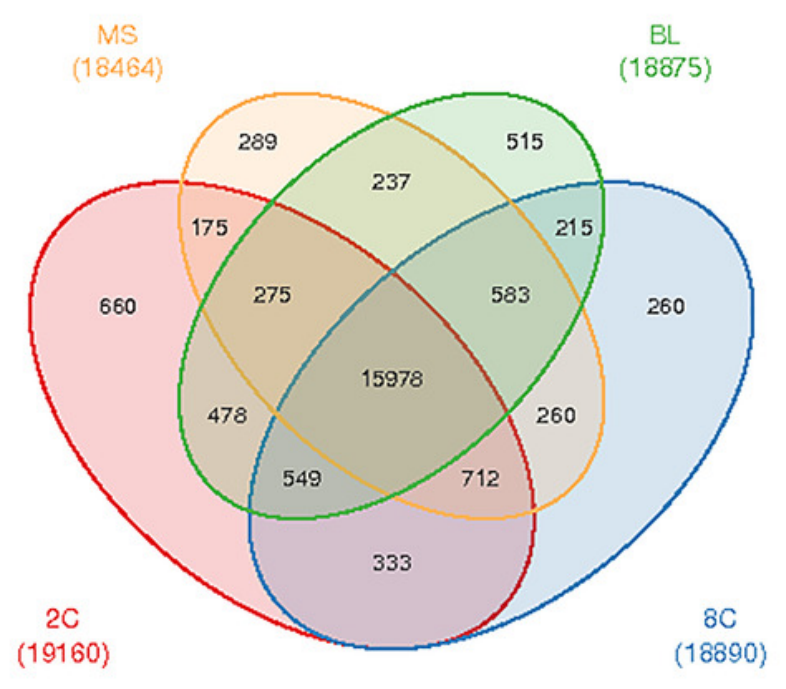

B

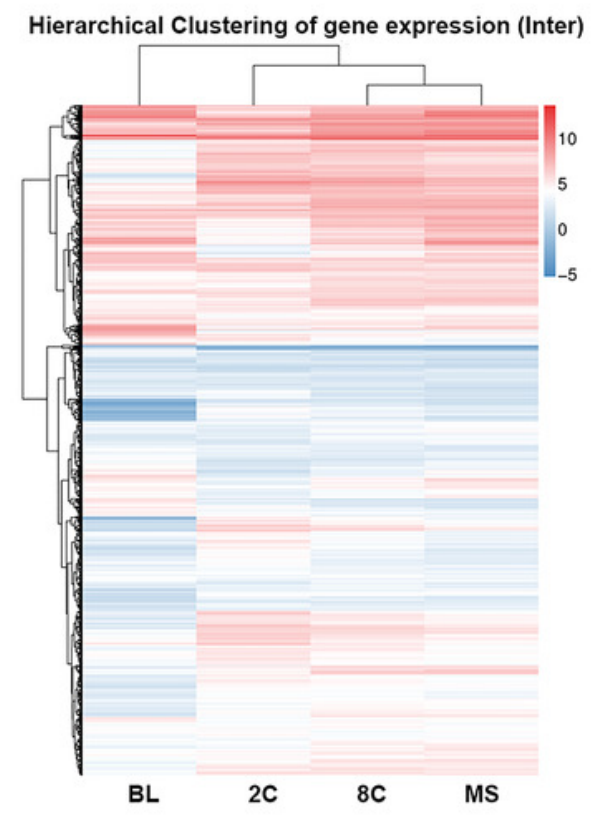


Figure 2

Transcriptome-wide time series cluster of expressions profiling

Transcriptome-wide time series cluster of expressions profiling through the different stages.

(A-D) Genes that were specifically expressed in 2C, 8C, MS and BL, respectively. (E) Genes

decreasing expression with PED progression. (F) Genes were increasingly expressed with PED progression. 
A

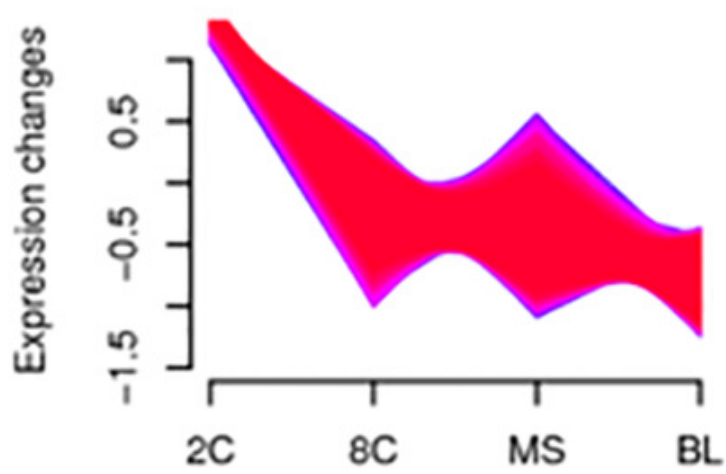

Time

C

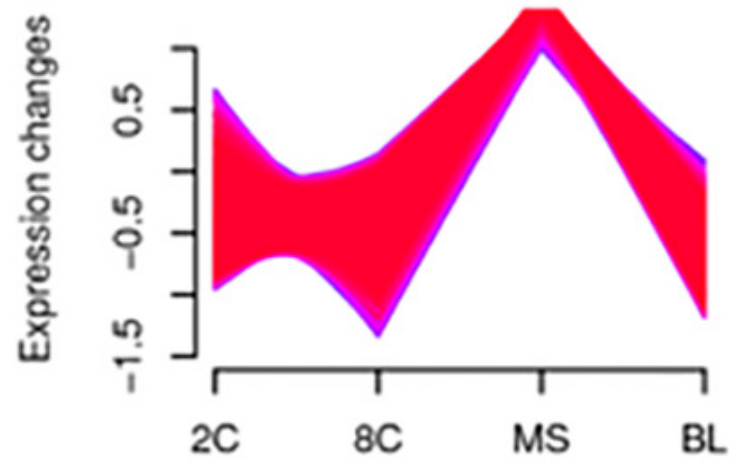

Time

E

Cluster 5

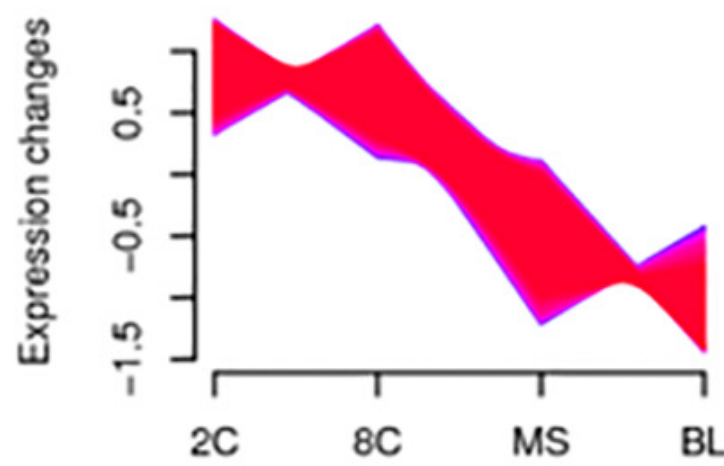

Time
B

Cluster 2

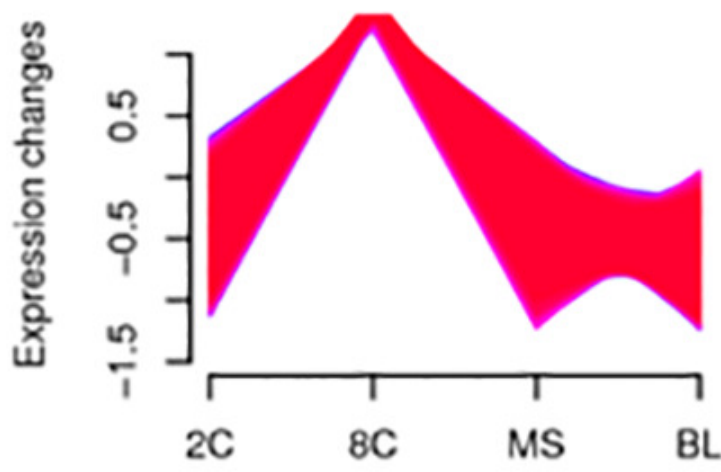

Time

D

Cluster 4

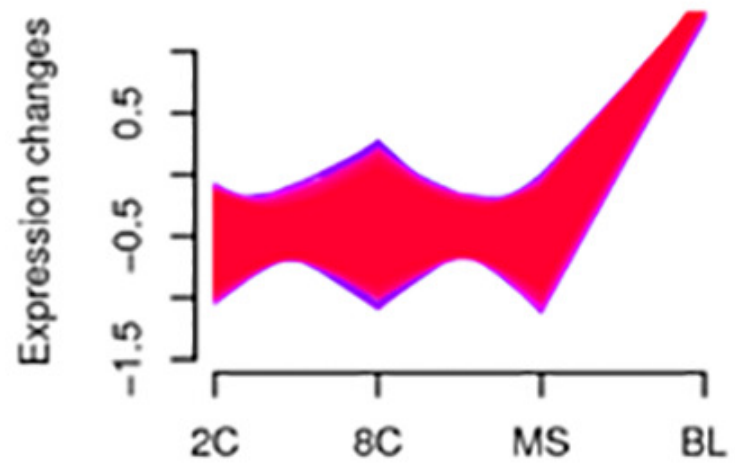

Time

F

Cluster 6

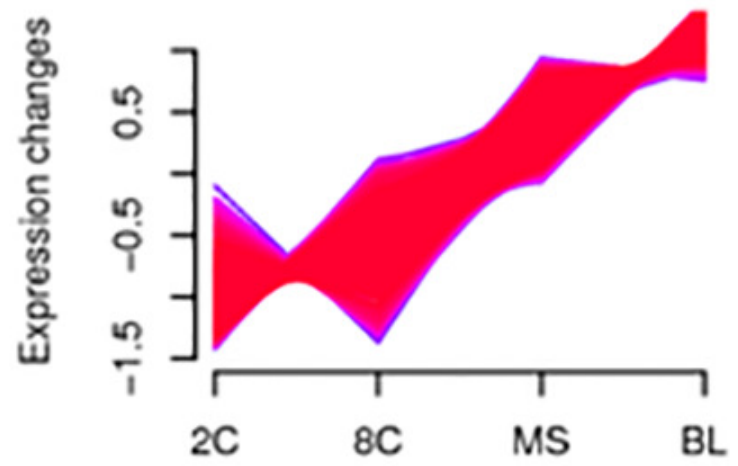

Time 


\section{Figure 3}

Ingenuity expression pattern analysis of specific genes involved in cell fate decisions

Expression pattern of genes involved in cell fate decisions in preimplantation embryo development. (A) Genes with high expression levels (FPKM: 15-90) in all four stages. (B) Genes with relatively low expression levels (FPKM <15). SD indicates three biological replicates. 
A

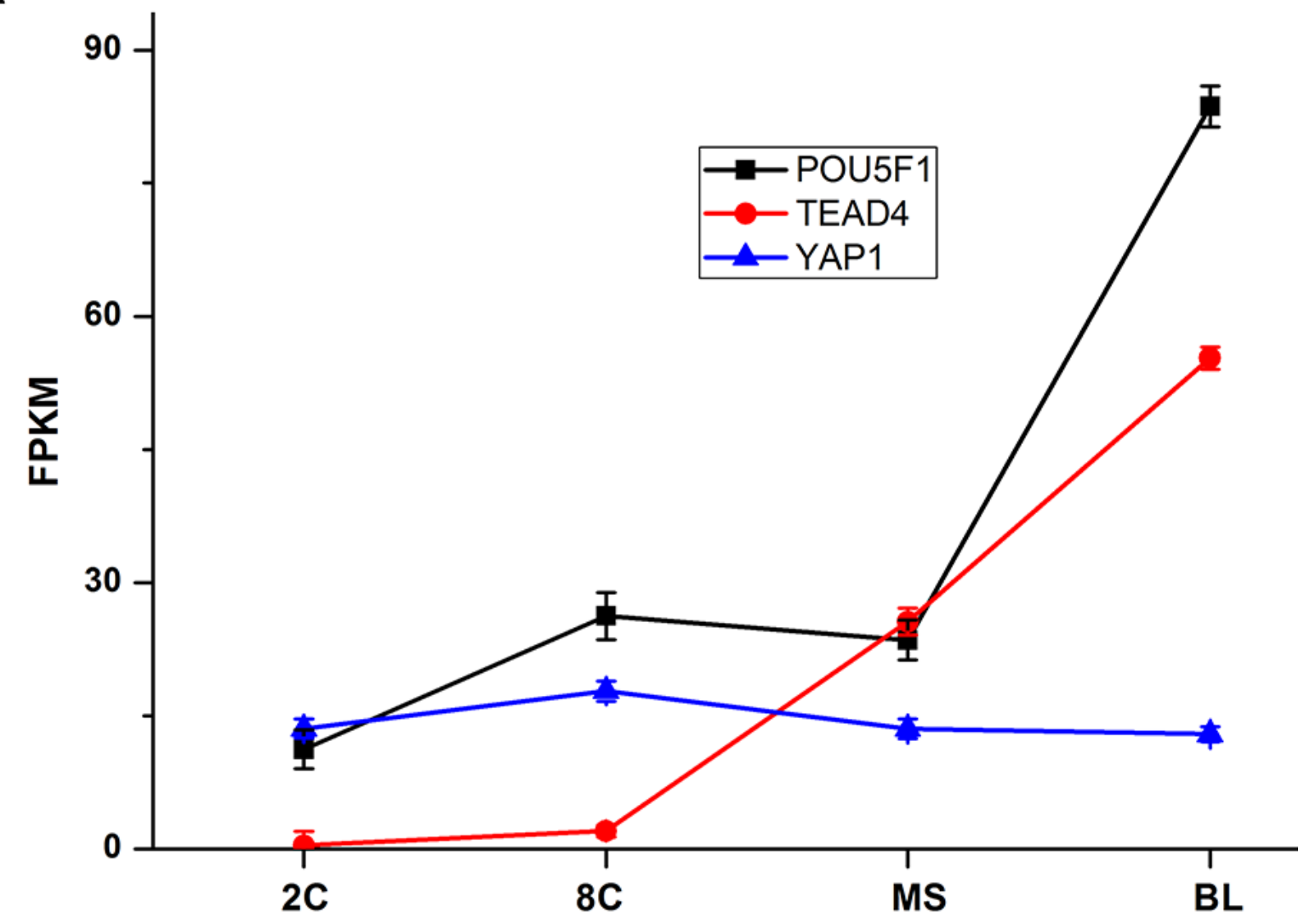

B

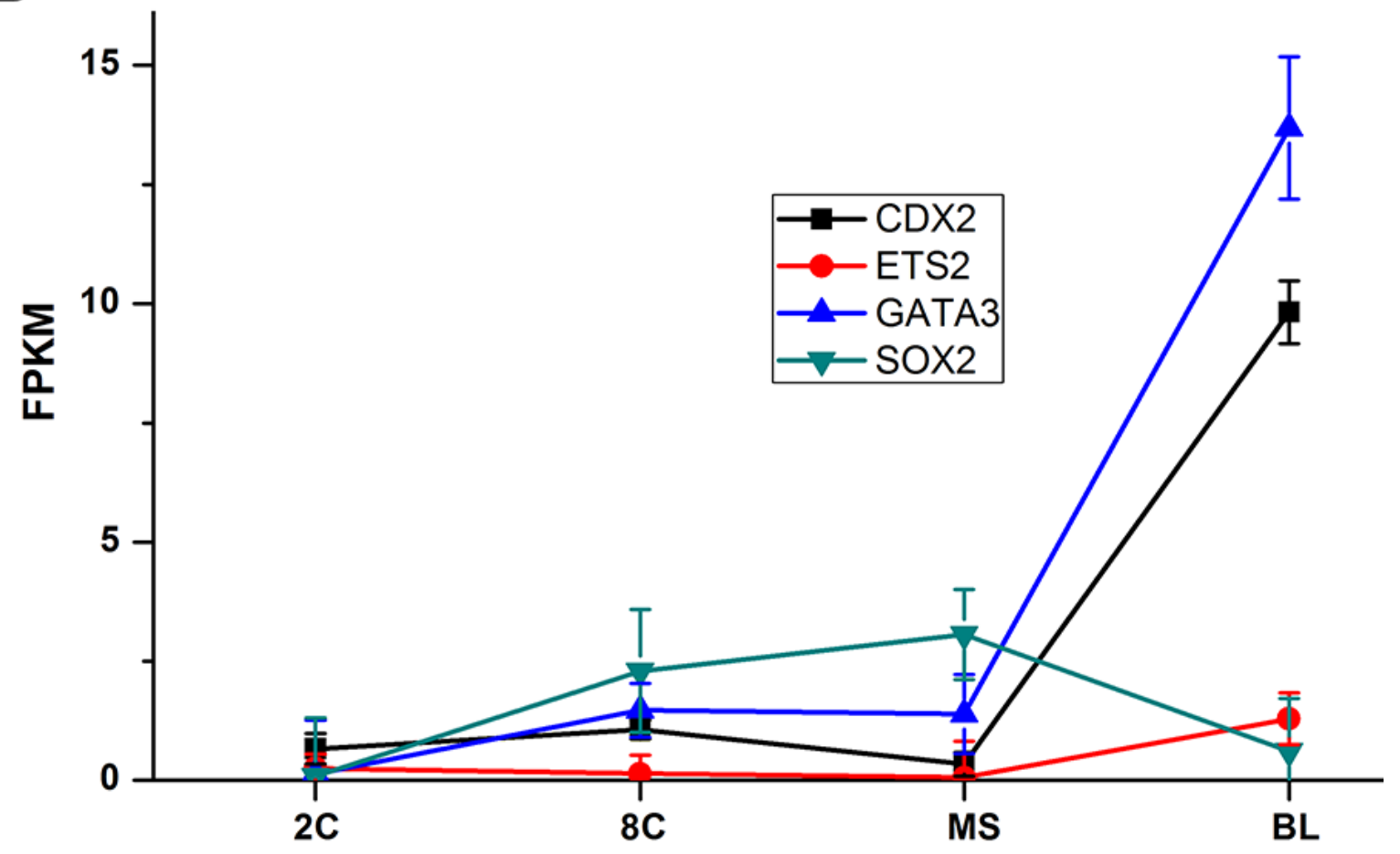




\section{Figure 4}

DEG analysis among four stages of PED

Differentially expressed gene (DEG) analysis. (A-F) MA plot of DEGs in each two-stages

comparison. (G) Up- and down- regulated DEGs in each comparison. (H) Cluster analysis of DEGs.

A

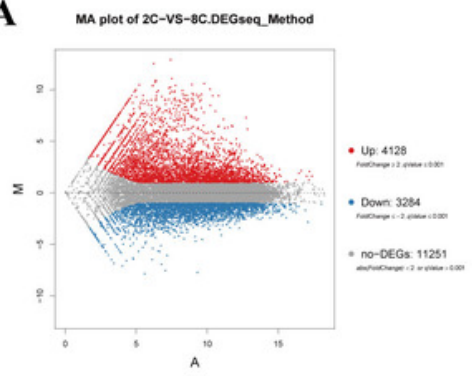

D

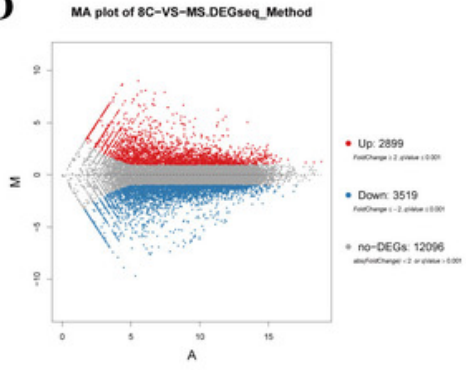

G

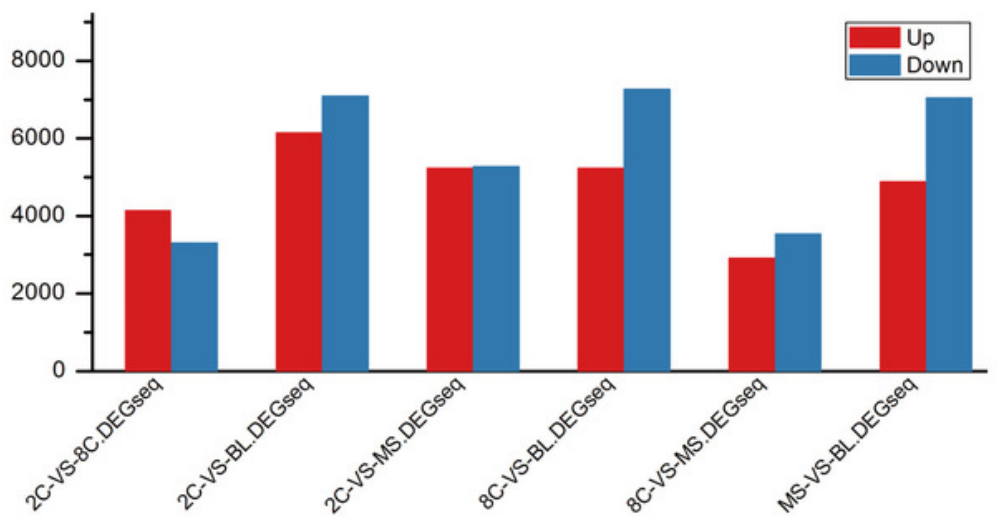

B

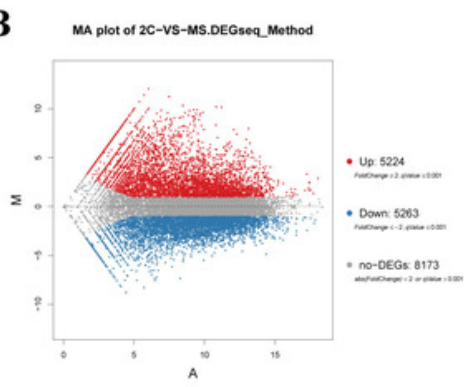

$\mathbf{E}$

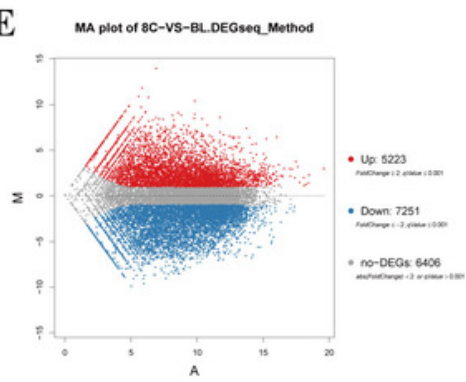

H
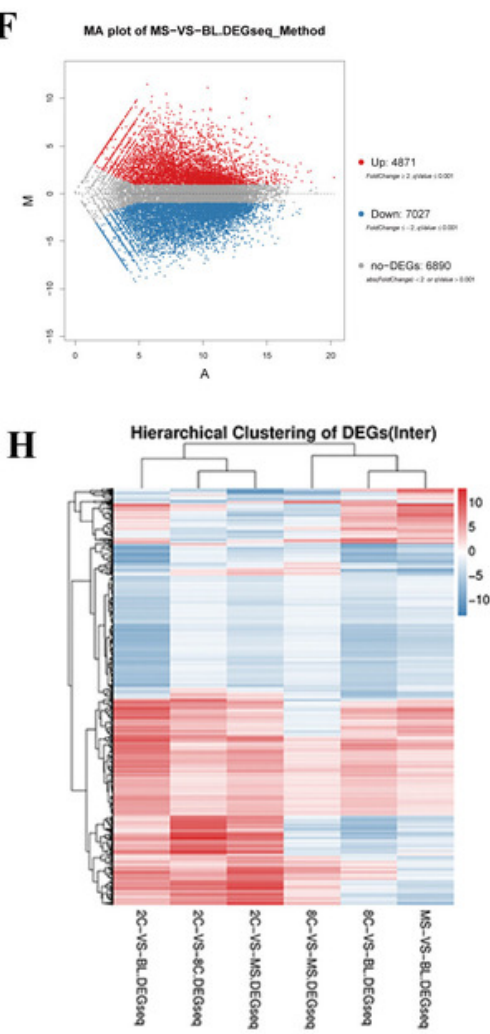
Figure 5

Differentially expressed transcription factor (TF) analysis

DEG transcription factor (TF) analysis . (A) Statistics of TF numbers and families. (B) Time series expression of TFs involved in cell linage control. SD indicates three biological replicates.

A

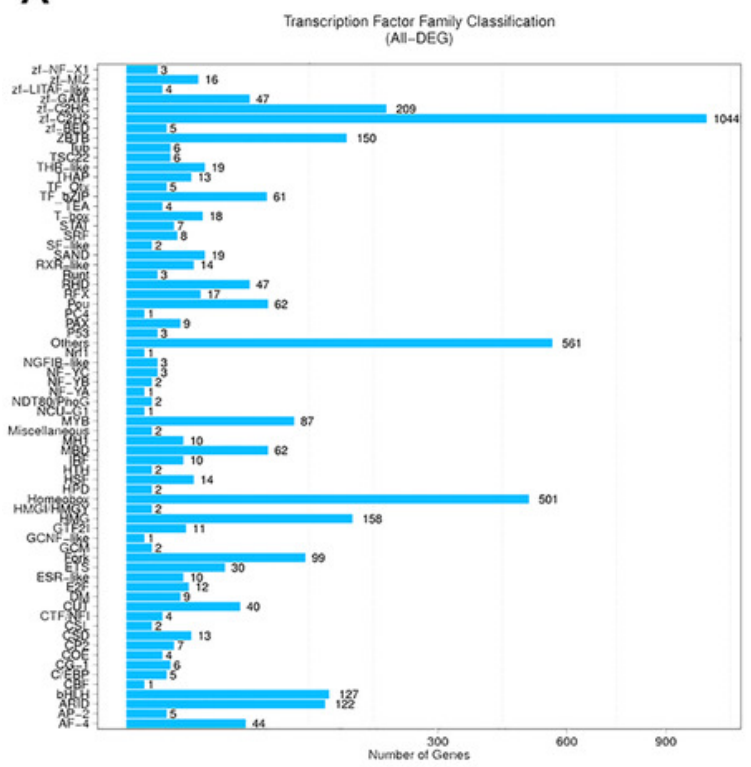

B

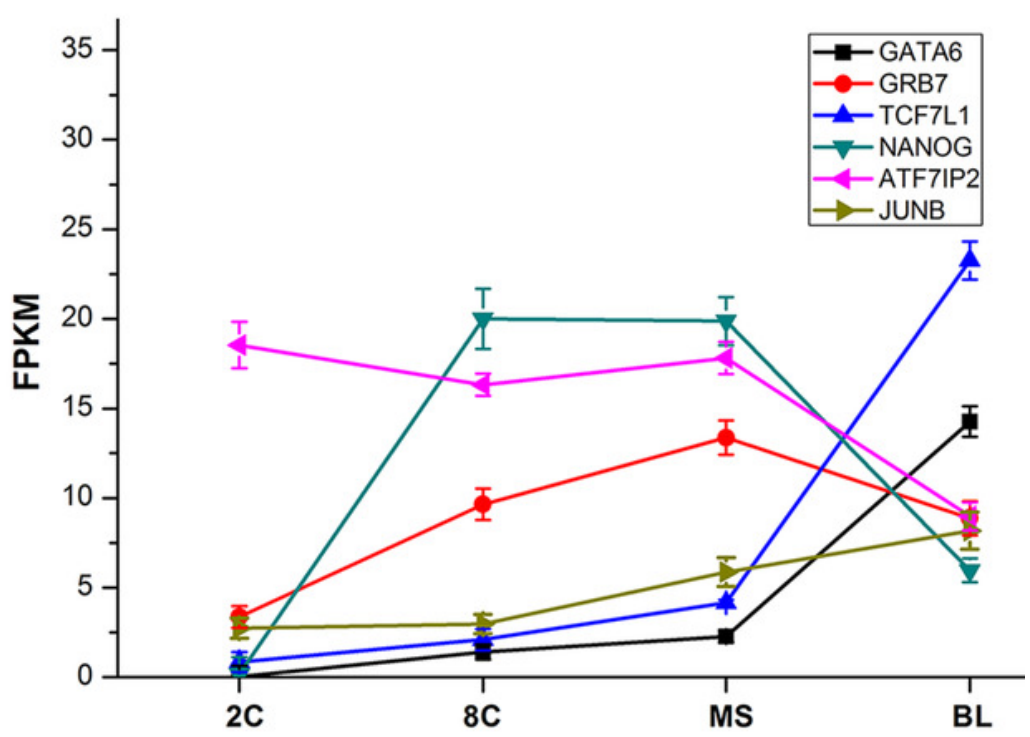


Figure 6

TFs regulatory network of cell lineage

TF interaction hierarchy of cell lineage genetic control in river buffalo (Rossant, 2018)

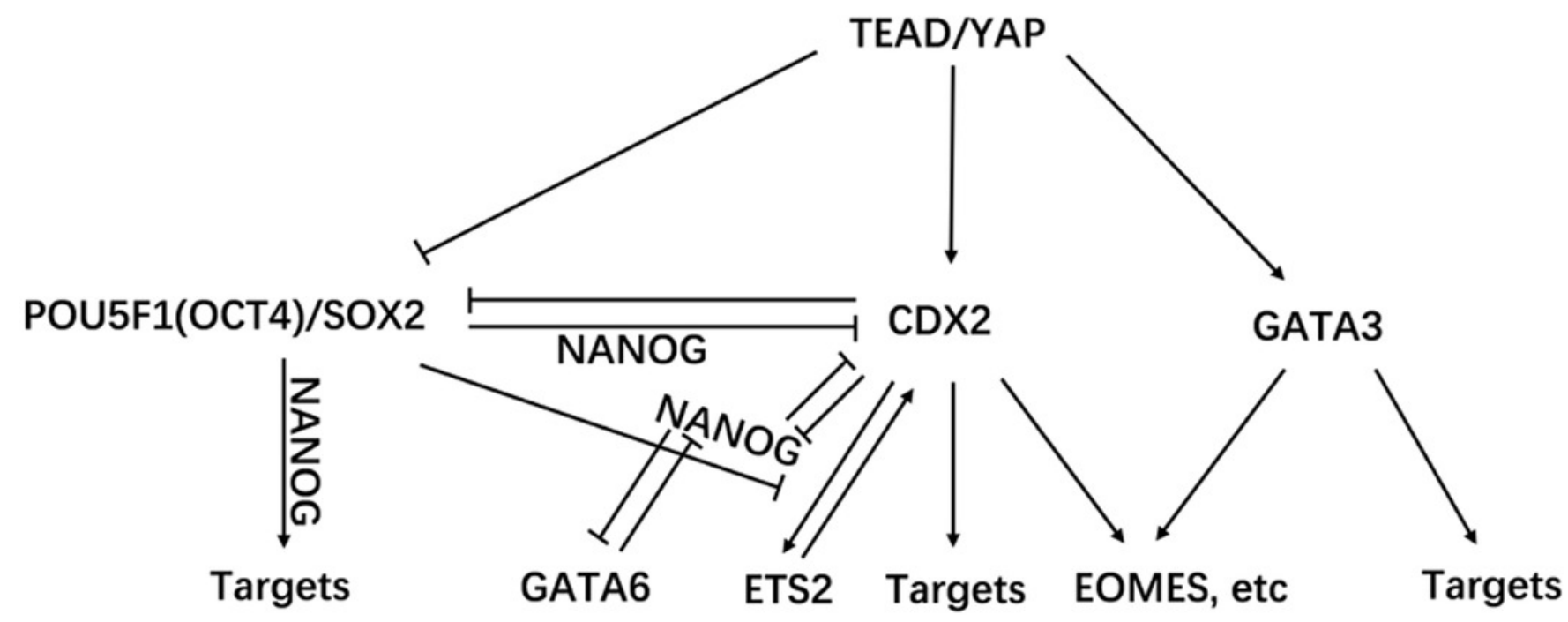




\section{Table $\mathbf{1}$ (on next page)}

Overview of RNA-seq reads and mapping of the reference genome ( $P E=100 \mathrm{bp})$. 


\section{Table 1}

2 Overview of RNA-seq reads and mapping of the reference genome ( $\mathrm{PE}=100 \mathrm{bp}$ ).

\begin{tabular}{lccccc}
\hline Sample & $\begin{array}{c}\text { Total Raw } \\
\text { Bases (Gb) }\end{array}$ & $\begin{array}{c}\text { Total Clean } \\
\text { Bases (Gb) }\end{array}$ & $\begin{array}{c}\text { Clean Reads } \\
\text { Ratio (\%) }\end{array}$ & $\begin{array}{c}\text { Total Mapping } \\
\text { Ratio }\end{array}$ & $\begin{array}{c}\text { Uniquely Mapping } \\
\text { Ratio }\end{array}$ \\
\hline M958_2C & 6.36 & 6.16 & 97.22 & $77.65 \%$ & $63.78 \%$ \\
M958_8C & 7.01 & 6.22 & 88.74 & $84.54 \%$ & $65.68 \%$ \\
M958_BL & 6.90 & 6.53 & 94.68 & $66.76 \%$ & $51.85 \%$ \\
M958_MS & 6.79 & 6.18 & 91.11 & $83.17 \%$ & $62.62 \%$ \\
M1088_2C & 6.94 & 6.48 & 93.47 & $88.61 \%$ & $73.02 \%$ \\
M1088_8C & 6.97 & 6.48 & 92.89 & $82.54 \%$ & $67.74 \%$ \\
M1088_BL & 7.01 & 6.28 & 89.58 & $78.06 \%$ & $57.03 \%$ \\
M1088_MS & 6.96 & 6.46 & 92.79 & $85.06 \%$ & $67.84 \%$ \\
M1172_2C & 6.56 & 6.2 & 94.46 & $82.41 \%$ & $69.36 \%$ \\
M1172_8C & 6.95 & 6.18 & 88.9 & $82.71 \%$ & $67.82 \%$ te \\
M1172_BL & 6.56 & 6.2 & 94.55 & $82.53 \%$ & $64.38 \%$ \\
M1172_MS & 6.95 & 6.38 & 91.75 & $85.76 \%$ & $67.78 \%$ \\
\hline
\end{tabular}

